\title{
Dynamic AI-Geo Health Application based on BIGIS-DSS Approach
}

\author{
Torky Sultan ${ }^{1}$, Mona Nasr ${ }^{2}$, Ayman E.Khedr ${ }^{3}$,Randa Abdo ${ }^{4}$ \\ ${ }^{1,2,3}$ (Dept of Information Systems, Faculty of Computers and Information, Helwan University, Cairo,Egypt) \\ ${ }^{4}$ (Dept of Geographic Information systems, Ministry of Health and population, Cairo,Egypt)
}

\begin{abstract}
Public health organizations use GIS on a daily basis for input, storage, manipulation, and output of geographic information which provides a powerful tool for public health assessment and monitoring in remote locations and developing countries [1]. Information technology is taking on a new level of importance due to its business intelligence application solutions. Our proposal is aimed at integrating these two different worlds in a single dynamic framework using web technology at health sector. Dynamic AI-Geohealth application based on BIGIS_DSS approach uses GIS tools and techniques to convert geographic information and analysis of data that becomes valuable information to make more informed business decisions and rational. Thus, the approach is not just a technical or business analytical process; But discipline which includes both. This paper explores the adopting Business Intelligence (BI) with Geographic Information System (GIS) to build a spatial artificial intelligence and predictive analytical approach. Also this paper will explores case research for implementation of proposed approach in developing countries like Egypt at health sector as dynamic health map web application. The proposed approach helps in solving spatial problem which faces decision makers at health sector.
\end{abstract}

Keywords: Business Intelligence (BI), Geographic information system (GIS), Decision support system (DSS), Artificial Intelligence (AI).

\section{Introduction}

Today GIS technology is increasingly being used in many fields of planning and research. The application of GIS has become increasingly in the design and evaluation of health care programs [3]. GIS is an innovative technology for generating type of information which needed to implement appropriate actions by Public health practices.

Business Intelligence (BI) is a broad category of world software that use IT applications and data processing analysis of huge sizes that can be excavated and extract knowledge that will help managers in the decision-making process of sections and various levels of management organization. BI is growing due to its great potential to streamline and enhance business processes. Despite its potential, BI faces two key problems, with attendant opportunities:

1-The first opportunity is delivering the right data to all the employee in the enterprise.

2-The second opportunity lies in decision effectiveness through advanced analytics.

The BI category has not provided managers and leaders with geographically enabled tools that easily support the retail management style. The dynamic, fast-paced environment of retail extends from the individual store, through the market and regional level, to the executive suite. Every day, health professionals face a challenge in making decisions with significant impact and that requires immediate and decisive decision [21].

These decisions should be based on the best available information and analysis, and must be coordinated to support decision-style self-evident to many of the health business leaders specialists. Therefore, GIS must be coupled with a BI, support development of powerful temporal-numerical routines. In addition, it must enable for the development of an interface that supports not only the combination of numerical and spatial information display, but also a temporal interactive easy-to-use environment for creating different types of numerical and spatial routines. As the result, the potential of this synergy is an approach that can significantly enhance spatial, temporal and numerical problem solving through predicative concept.

Predictive analytics are used to determine the probable future outcome of an event . Data mining important branch concerned with the prediction of future probabilities and trends. Predictive analytics are used to automatically analyze huge data with different variables; it covers decision trees, clustering, testing, market basket analysis, genetic algorithms, neural nets, text mining, hypothesis decision analytics, regression modeling, and more .In proposed predictive modeling, Many predictions are collected in the predictive model, with an acceptable level of reliability through collected data, a statistical model is formulated, predictions are made, and the model is validated (or revised) as additional data become available. 
Proposed spatial predictive analytics approach combines knowledge of business, analysis of spatial data, geoprocessing and statistical analytical techniques to apply with business data to achieve visions. These visions will help health institutions understand how decision makers can take right decision in the right time

\section{Related Work}

In general, into GIS application the information is divided over multi thematic layers. The information in each layer consists of spatial data and attribute data. We will use the vector model for spatial data representation.

Although some researchers have pointed out the advantages of combining GIS and OLAP, not much work has been done in this field. They process the combining of GIS and OLAP but without giving a formal model include multi predict operations and achieve analytics insights, this current combining between OLAP and GIS just produce multi reports and simple analytics process but not in different time frame. Other proposals in the area of indexing spatial and spatio-temporal data warehouses [11,12] combine indexing with preaggregation, resulting in a structure denoted Aggregation R-tree (aR-tree), In summary, the discussion above shows that the problem of introduce integrating spatial and warehousing information in a single framework is still in its infancy.

\section{The Intersection of BI and GIS}

In past decades, BI,AI and GIS technologies have followed separate development and implementation paths. In health sector, Decision makers request for a more complete operational picture and the ability to be more proactive have led to the combination of these technologies to have suitable AI tool for DSS.

Today, there are two dominant approaches that are used to produce maps and proximity analysis into business intelligence and business applications. The first dominant approach uses integration with a geographic information system, parallel to standard business and BI applications as a two separate software. The second dominant approach to integrate GIS with OLAP applications is to access web-based spatial systems and display outcomes through general location services . There are some limitations to this approach as follow:

Spatial analysis and access is limited to what is accessible through the APIs;

The available parameters limit the breadth of the analysis, and the analysis cannot be broadened without technical personnel developing more parameters and limited to geographic hierarchies available on online service; Sometimes, there are need to transfer data from internal system to an external system and back to perform spatial design and analysis. The big problem in this approach is Doing tasks limited to that delivered by the map service. In addition, it must enable for the development of an interface that supports not only the combination of numerical and spatial information display, but also a temporal interactive easy-to-use environment for creating different types of numerical and spatial routines. Therefore, having a spatial temporal analysis capability could provide an alternate way to look at public health information. Presenting information with a spatial component triggers a different thought process than seeing the same information on a table or a grid and guide decision maker brainstorm for new possibilities.

\section{A proposed Approach}

In our proposed approach we will use currently web technologies, with standards components simplify the adoption of GIS capabilities into BI applications, with reports and advanced analytics to produce results as shown on Figure 1.

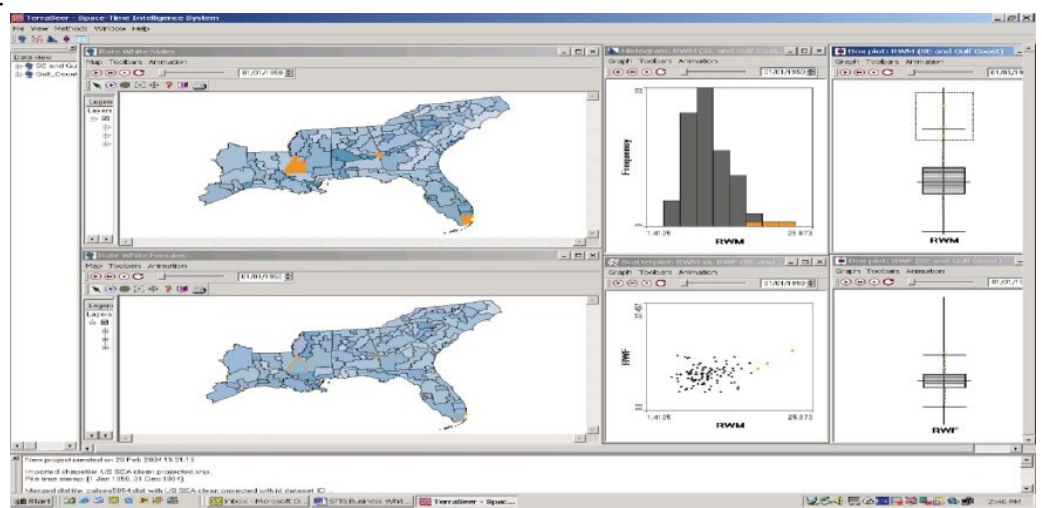

Figure. 1: The Proposed Approach with Different software

BI-GIS Approach consists of a set of spatial models, description and analysis methodologies that systematically exploit the available data to retrieve information. Knowledge and advice useful in supporting complex decision making processes according to many criteria and alternatives. We have implemented The BI-GIS approach on a system named Dynamic health map wëb application as ä case study to verify its improvement . 
The proposed model for BI-GIS approach consists of five components as follows :Business objectives and problem definition component .,Spatial Business data resources components .,Unified geodatabase component, Spatial business intelligence processing unit component, Evaluation and selection the appropriate and optimal business decision component .BI-GIS approach is able to apply in different business areas such as education, industry, energies ,communication economy ......etc

-The architecture model for main components of BI-GIS approach

The proposed spatial analytical approach which adopted to cover three main health planning issues. These issues are tackling health inequalities through geospatial monitor for inequalities in distribution of health units and its services, support decision-making with predictive analytics for common health indicators, and geoprocessing for input layers through dynamic health map and motion charts to support decision making.

BI-GIS Model for health Inequity as a part from The proposed spatial analytical approach

From the perspective of the researcher, Definition of health equity is the availability of the health service in the right place and at the right price with the necessary quality. So, the researcher view that the quality of health

service hubs are available in the three axes:

1 - Location of health Unit, it must be distributed according to international health standard to cover all governorates area

2 - Trained manpower like doctors, nurses and employees with high recommended aspects according to HL7 methodology

3 - Health services and medical equipments must be available with high performance to support quality of health service to all patients

And these hubs must be available with the existence of two conditions

1 - The time to introduce the health service for the patient

2 - The cost appropriate for the patient with the availability of support from the State

The researcher believes that when the patients be satisfied about the introduced health services ,this is the core of model success, The research will define BI-GIS according to the previous components of BI-GIS approach as " a set of spatial intelligence and predictive analytical models, descriptions, and advanced analysis methodologies that systematically exploit the availability spatial and non-spatial data to retrieve information ,knowledge and predicted advice useful in supporting complex decision making processes according to many criteria and alternatives. Figure 2 illustrates the components of BI-GIS according to the explanation and discussion in the previous section. This allows the BI-GIS system to produce any kind of spatial or non-spatial query that might be required, no matter how detailed. Figure 3 illustrates sample of BI-GIS system analysis.

\section{Dynamic AI-Geohealth Application as a case study}

Dynamic AI-Geohealth web application has made to support decision maker at health sector in Egypt. Dynamic health map web application is the implementation of the proposed approach. This application can used to create, edit, and manage health maps include health services, health indicators ,health inequity areas , disease, models for solving health spatial problems, advanced analysis through predictive tool ,etc.The proposed approach was tested in Ministry of Health units at Egypt and compared the result after the implementation with another approach called OLAP-GIS.

\section{-Approach Method}

BIGIS-DSS proposed approach developed at Egyptian Ministry of Health, we were compared it with current IT for analysis research belong CHA. About this research, current research was considered the adoption of GIS and OLAP ("OLAP-GIS") together. Researchers, and doctors in the computer sciences faculty were participated in this research. The participants were divided into working groups and each group was concerned with a range of tasks with the necessary tools to assess where documentary film included to explain the proposed system and the current system, criteria for comparison between the two systems in terms of time and efficiency in fulfilling the tasks required and acceleration performance 


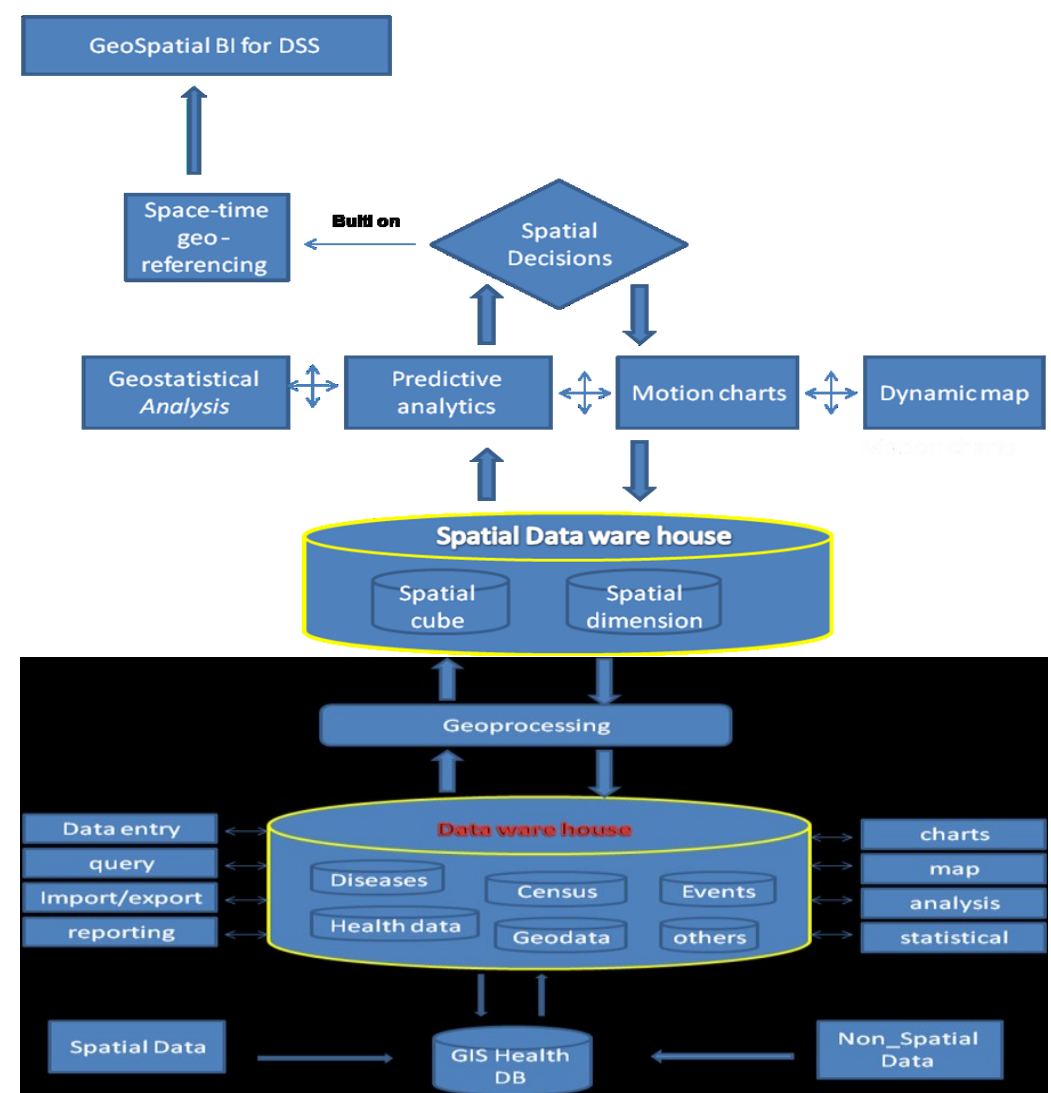

Figure 2 : Synthesis model for Business Intelligence and Geospatial Information System Methodology Phases

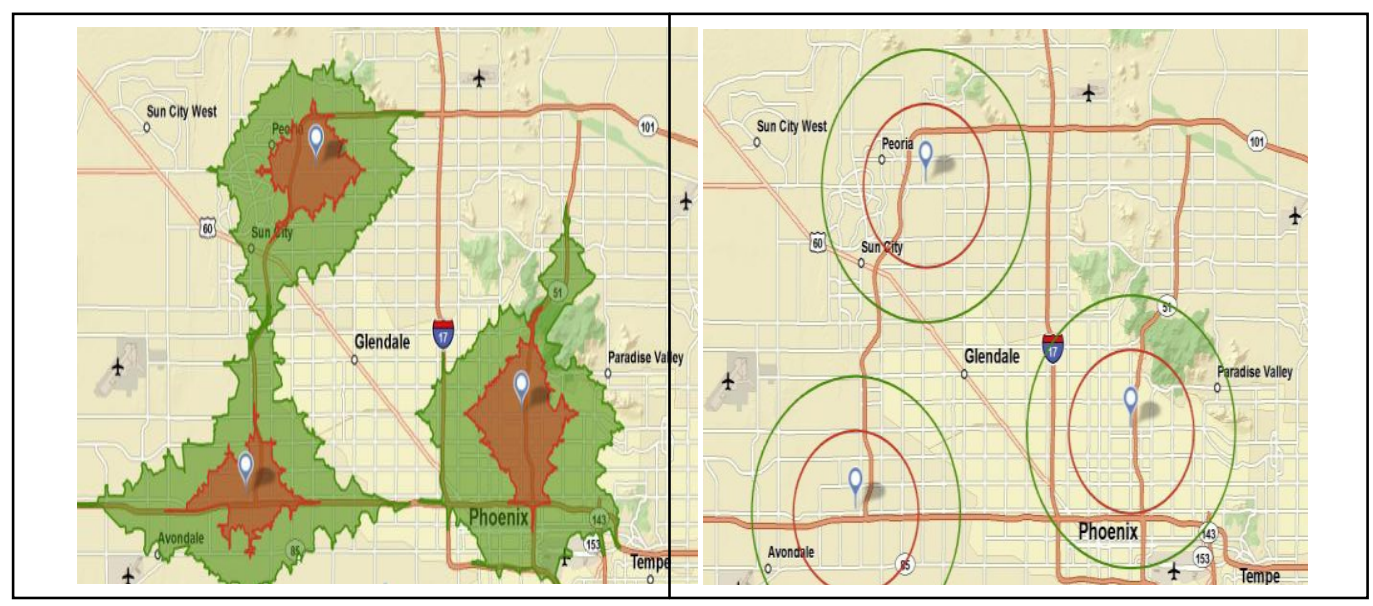

Figure 3: Drive time spatial query and Ring spatial query

\section{Results of the Approach}

According to a recent survey from BIGIS-DSS Research, $38 \%$ of Ministry of Health sectors surveyed are practicing advanced analytics today, whereas $45 \%$ say they'll be practicing it within three years. Whereas $17 \%$ prefer using the traditional way in displaying map and make analysis through deferent tools. BIGIS-DSS was Predictive analytics from OLAP-GIS for advanced analytics; BIGIS-DSS can produce statistics which you can predict different prospects of same situations. After the participants had finished the tasks ,the Descriptive results indicated that when they using BIGIS-DSS as compared to OLAP-GIS they had succeeded in performing all the tasks in less time and greater performance. Table 1 illustrate proposed maturity levels 
Table 1 :Egyptian Health program proposed maturity levels

\begin{tabular}{|c|c|c|c|c|c|c|}
\hline \# & Level & Entities & Department & Infrastructure & $\begin{array}{l}\text { Implementa } \\
\text { tion } \\
\text { Period }\end{array}$ & $\begin{array}{l}\text { Maturit } \\
\mathbf{y} \\
\text { Period }\end{array}$ \\
\hline 1 & $\begin{array}{l}\text { Hospital } \\
\text { Administration } \\
\text { Level }\end{array}$ & $\begin{array}{l}\text { Providers }+ \\
\text { Payor } \\
+ \text { call center }\end{array}$ & $\begin{array}{l}\text { Patient enrollment } \\
\text { Patient Administration } \\
\text { Billing } \\
\text { Claiming }\end{array}$ & Internet & $12 \mathrm{M}$ & $9 \mathrm{M}$ \\
\hline 2 & $\begin{array}{l}\text { Enterprise } \\
\text { Level }\end{array}$ & $\begin{array}{l}+ \text { MOHP } \\
+ \\
\text { Beneficiary } \\
\text { portal }\end{array}$ & $\begin{array}{l}\text { Payor monitoring (Fraud } \\
\text { management) } \\
\text { MOHP supply chain } \\
\text { electronic claims } \\
\text { E-payments processing }\end{array}$ & Internet & $12 \mathrm{M}$ & $9 \mathrm{M}$ \\
\hline 3 & $\begin{array}{l}\text { EMR Basic } \\
\text { Level }\end{array}$ & $\begin{array}{l}+ \text { Lab } \\
+\quad \text { External } \\
\text { Pharmacy }\end{array}$ & $\begin{array}{l}\text { Laboratory Information System } \\
\text { Radiology Information System } \\
\text { Pharmacy } \\
\text { Quality assurance (MOHP) }\end{array}$ & $\begin{array}{l}\text { Secure HL7 based } \\
\text { Communication }\end{array}$ & $9 \mathrm{M}$ & $12 \mathrm{M}$ \\
\hline 4 & $\begin{array}{l}\text { Regional/Nation } \\
\text { al Level }\end{array}$ & $\begin{array}{l}+ \text { Regional } \\
\text { managemen } \\
\mathrm{t}\end{array}$ & $\begin{array}{l}\text { Regional information } \\
\text { Regional monitoring } \\
\text { data warehouse } \\
\text { Prediction services }\end{array}$ & $\begin{array}{l}\text { Fully connected } \\
\text { and } \\
\text { paperless - SaaS } \\
\text { Model }\end{array}$ & $12 \mathrm{M}$ & $12 \mathrm{M}$ \\
\hline 5 & $\begin{array}{l}\text { Clinical } \\
\text { Decision } \\
\text { Support Level }\end{array}$ & + & Automated DSS & & $6 \mathrm{M}$ & $0 \mathrm{M}$ \\
\hline 6 & $\begin{array}{l}\text { Clinical } \\
\text { Research Level }\end{array}$ & $\begin{array}{l}\text { + Pharma } \\
\text { Companies }\end{array}$ & $\begin{array}{l}\text { Clinical Trials } \\
\text { Clinical Data Research based on } \\
\text { drug prescriptions } \\
\text { and reactions }\end{array}$ & $\begin{array}{l}\text { RaaS } \\
\text { Mode }\end{array}$ & $6 \mathrm{M}$ & $0 \mathrm{M}$ \\
\hline
\end{tabular}

\section{Evaluation of BIGIS-DSS Approach}

The aim of using BIGIS-DSS approach by health sector professionals in developed countries frequently analyze public health data in order to answer questions which identify health priorities. The steps in the process might be the:

- Identification of the areas where in a particular disease is prevalent?

- Identification of some clues about the possible factors that is responsible for a particular disease as a numerical data;

- Identification of the additional support for facilities and staff;

- Identification of in which area the infant mortality rate is high;

- Identification of the areas where in water related diseases are prevalent;

- Identification of the areas where the birth rate is high;

- Comparison of numerical data with spatial data within the community against the bordering community using statistical methods for adjustment relative risk and odds ratios;

- Describe results using tables, maps or graphs.

The first step is a spatial component can be done by using a map. The second step, , is fully numerical. However, the next step. Like the first step, this can be done through a map. Other steps mix between spatial data and non-spatial data in these counties. Using statistical measures and adjustments are performed in order to determine health priorities.

We had a survey of Ministry of health researchers \&professionals, and we found that many of them use programs such as statistical packages, databases, and sometimes GIS software[15]. We decided to conduct an evaluation comparing between BIGIS-DSS to information technology (IT) that is commonly used, including traditional analytical tools and GIS because The potential of implementation for BIGIS-DSS approach in health sector analysis is not well understood. Assuming that the use of BIGIS-DSS system would greatly facilitate the analysis of health data when considering the accuracy efficiency, and user satisfaction. Table 2 display the Evaluation of BIGIS-DSS Approach by compare it with the approach called OLAP-GIS which developed at the University of Pittsburgh. 
Table 2: Comparison between BIGIS-DSS as proposed approach and OLAP-GIS approach

\begin{tabular}{|c|c|c|}
\hline & $\frac{\text { OLAP-GIS APPROACH }}{\text { (Reporting and OLAP) }}$ & $\begin{array}{l}\text { BIGIS-DSS APPROACH } \\
\text { (Advanced Analytics, Both } \\
\text { Query-Based and Predictive) }\end{array}$ \\
\hline Business Method & $\begin{array}{l}\text { Performance management for } \\
\text { Business entities, relative to a business plan. }\end{array}$ & $\begin{array}{l}\text { Develop new products like maps for Health } \\
\text { services, health indicators, etc. Reduce cost, } \\
\text { risk, fraud. }\end{array}$ \\
\hline $\begin{array}{l}\text { Information } \\
\text { Purpose }\end{array}$ & $\begin{array}{l}\text { Update known facts. } \\
\text { Quantify past performance. }\end{array}$ & $\begin{array}{l}\text { Infer unknown facts and relationships. } \\
\text { Quantify future probabilities. }\end{array}$ \\
\hline Output & $\begin{array}{l}\text { Historical standard reports, } \\
\text { dashboards, metrics, KPIs, } \\
\text { Cubes for OL AP, etc. }\end{array}$ & $\begin{array}{l}\text { Predictive models, scores, forecasts. } \\
\text { Results of complex queries. Insights. }\end{array}$ \\
\hline Queries & Known, simple queries that are easily optimized. & $\begin{array}{l}\text { Queries that becomes very complex as they } \\
\text { evolve via iteration. }\end{array}$ \\
\hline $\begin{array}{l}\text { Volume per } \\
\text { Query }\end{array}$ & $\begin{array}{l}\text { Small (usually less than } \\
\text { A gigabyte). }\end{array}$ & Large (possibly terabytes). \\
\hline $\begin{array}{l}\text { Data mining } \\
\text { process }\end{array}$ & Limited and complex & Large and complex \\
\hline Analytical tools & Analysis in limited areas & $\begin{array}{l}\text { Analysis and Linkage between different } \\
\text { areas, discovery of unknown facts and } \\
\text { relationships }\end{array}$ \\
\hline $\begin{array}{l}\text { Efficiency } \\
\text { purpose }\end{array}$ & $\begin{array}{l}\text { High in specific and limited areas. } \\
\text { OL AP's purpose is to quickly } \\
\text { Answer multi-dimensional queries of summarized } \\
\text { data. } \\
\text { You can discover only what's already in a cube. }\end{array}$ & High in large areas-multidimensional areas \\
\hline Data Models` & $\begin{array}{l}3 \mathrm{NF} \text { data model to model the enterprise with views } \\
\text { for application flexibility. }\end{array}$ & $\begin{array}{l}\text { 3NF of source data. Models demanded by } \\
\text { analytic tools. Predictive models and } \\
\text { scores. }\end{array}$ \\
\hline GeodataBase & $\begin{array}{l}\text { organizations with a warehouse } \\
\text { focused on reporting and OL AP will need to extend } \\
\text { or complement } \\
\text { It with a separate analytic database to support an } \\
\text { analytic workload and appropriate data. And the } \\
\text { analysis cannot be broadened without technical } \\
\text { personnel developing more parameters. }\end{array}$ & $\begin{array}{l}\text { Has advanced analytics tool for Discover } \\
\text { relationships. }\end{array}$ \\
\hline
\end{tabular}

\section{CONCLUSION AND FUTURE WORK}

Using BIGIS-DSS approach, all tasks been completed more efficiently, with a greater rate of success, and with higher satisfaction from user, than the combined use of OLAP and GIS. The Outcomes of this research indicate a potential for BIGIS-DSS decision support systems as a valuable tool for the analysis of health data.

Coupled with web map components as an implementation for proposed approach, Each product BI can include maps visualization and analysis of proximity and location-oriented search, and services on the Internet in real time in the same infrastructure, and without any complexity greater than what is required to see the other analytical tools. Another factor that affects the cost and effort of implementing business intelligence applications aware of is the expense associated with managing the data itself. Organizations are becoming aware that the databases projects now enable them to manage and exchange geospatial data in the same database environment their business and operational information. In addition to this approach, and enhance the data in the enterprise database can further simplify the integration of maps and spatial analysis in BI and other applications, while reducing or eliminating dependence on geographic information systems (GIS) software specialist. Using this approach allows analysis of geospatial to move from a world of specialization in the field of service everywhere element to rely on the data available for analysis, rather than the complex, and single-purpose application.

In addition to this approach, and enhance the data in the enterprise database can further simplify the integration of maps and spatial analysis in BI and other applications, while reducing or eliminating dependence on geographic information systems (GIS) software specialist. Using this approach allows analysis of geospatial to move from a world of specialization in the field of service everywhere element to rely on the data available for analysis, rather than the complex, and single-purpose application.

The results demonstrate the potential for BIGIS_DSS in health sector analysis. Future work will explore the impact of the BIGIS_DSS system in other areas of public health as using BIGIS_DSS to develop slums in development countries. 


\section{References}

[1]. Aschengrau, A., et al. 2008. Prenatal Exposure to Tetrachloroethylene-Contaminated Drinking Water and the Risk of Adverse Birth Outcomes. Environmental Health $\quad$ Perspectives $116 \quad$ (June) http://www.pubmedcentral.nih.gov/articlerender.fcgi?artid=2430239\&tool=pmcentrez.

[2]. Bastrup, R., et al. 2008. Arsenic in Drinking-Water and Risk for Cancer in Denmark. Environmental Health Perspectives 116 (February) (2): 231-237. http://www.pubmedcentral.nih.gov/articlerender.fcgi?artid=2235208\&tool=pmcentrez.

[3]. Brody, J., et al. 2006. Breast Cancer Risk and Drinking Water Contaminated by Wastewater: A Case Control Research. Environmental Health: 5:28. http://www.ehjournal.net/content/5/1/28.

[4]. DeWeese, A., et al. 2007. Reducing Risks to the Anishinaabe from Methylmercury: A GIS-Based Fish Consumption Advisory Program for Walleye. Presented at the American Public Health Association annual meeting. http://apha.confex.com/apha/135am/techprogram/paper_153890.htm.

[5]. Fischer, T. 2006. Developing an Underground Storage Tank Inspection Prioritization Tool Using GIS. Presented at the Esri International User Conference. proceedings.esri.com/library/userconf/proc06/papers/abstracts/a1673.html.

[6]. Fleming, H., and H. Harding. 2007. Groundwater Arsenic Concentrations and Cancer Incidence Rates: A Regional Comparison in Oregon. Presented at the American Public Health Association annual meeting. http://apha.confex.com/apha/135am/techprogram/paper_153271.htm.

[7]. Gordon, L. 2009. Assessing the Risks to Public Health from Contamination in Potable Wells Using the Geographic Information Systems (GIS). Presented at the NEHA conference. www.neha.org.

[8]. Hughes, S., et al. 2004. Using a Geographical Information System to Investigate the Relationship between Reported Cryptosporidiosis and Water Supply. Int Jealth http://www.pubmedcentral.nih.gov/articlerender.fcgi?artid=506784\&tool=pmcentrez.

[9]. Jacob, B., et al. 2008. Hydrological Modeling of Geophysical Parameters of Arboviral and Protozoan Disease Vectors in Internally Displaced People Camps in Gulu, Uganda. Int Jealth Geogr7:11. http://www.pubmedcentral.nih.gov/articlerender.fcgi?artid=2275725\&tool=pmcentrez.

[10]. Januleuwicz, P., et al. 2008. Risk of Learning and Behavioral Disorders Following Prenatal and Early Postnatal Exposure to Tetrachloroethylene (PCE)-Contaminated Drinking Water. Neurotoxicology and Teratology 30 (3): 175-185. http://www.pubmedcentral.nih.gov/articlerender.fcgi?artid=2494864\&tool=pmcentrez.

[11]. Jones, M. 2009. Mapping Water Sources in Rwanda Helps Effort to Reduce Child Mortality. HealthyGIS (Summer). esri.com/library/newsletters/healthygis/healthygis-summer09.pdf.

[12]. Kurakina, N. 2008. Analyzing the Environmental Impact of Water Bodies in Russia: River Pollutants Monitored with GIS. ArcNews (Summer). esri.com/news/arcnews/summer08articles/river-pollutants.html.

[13]. Kravets N, Hadden W: The accuracy of address coding and the effects of coding errors. Health Place 2007, 13:293-298.

[14]. Matthew, Laurence Scotch, AN OLAP-GIS SYSTEM FOR NUMERICAL-SPATIAL PROBLEM SOLVING IN COMMUNITY HEALTH ASSESSMENT ANALYSIS, University of Pittsburgh, 2006

[15]. Meliker, J., et al. 2008. Validity of Spatial Models of Arsenic Concentrations in Private Well Water. Environmental Research 106 (January) (1): 42-50. http://www.pubmedcentral.nih.gov/articlerender.fcgi?artid=2271042\&tool=pmcentrez.

[16]. Mitchell, R. A Social Map of the Gulf Oil Spill. http://blogs.computerworld.com/16078/a social map of the gulf oil spill.

[17]. Monaco Va1,parmanto Bambang, Scotch Matthew, Evaluation of SOVAT: An OLAP-GIS Decision Support System for sisylanA ataD tnemssessA htlaeH ytinummoC, gnikaM noisiceD dna scitamrofnI lacideM CMB , Year :2008,issue 1,pp:10, Vol:8

[18]. Philip, Russom, Data Requirements for Advanced Analytics, TDWI Checklist report, 2008

[19]. Refaat M Kamell and Samir M Wassif, Population Problem In Egypt As One of The Priority Health Problems In Tropical Areas Surgery Department, Faculty of Medicine, Ain-Shams University and Community Medicine Department, Faculty of Medicine, Zagazig University, Egypt_2008

[20]. Rushton G, Armstrong M, Gittler J, Greene B, Pavlik C, West M, Zimmerman D. Boca Raton, Statistical methods for incompletely and incorrectly geocoded cancer data. In Geocoding Health Data. PL: CRC Press, 2008

[21]. Osei, F., and A. Duker. 2008. Spatial and Demographic Patterns of Cholera in Ashanti Region-Ghana. Int J Health Geogr 7:44. http://www.pubmedcentral.nih.gov/articlerender.fcgi?artid $=2533654 \&$ tool=pmcentrez.

[22]. Osei, F., and A. Duker. 2008. Spatial Dependency of V. cholera Prevalence on Open Space Refuse Dumps in Kumasi, Ghana: A Spatial Statistical Modeling. Int J Jealth Geogr http://www.pubmedcentral.nih.gov/articlerender.fcgi?artid=2628349\&tool=pmcentrez.

[23]. Simental, L., and J. Martinez-Urtaza. 2008. Climate Patterns Governing the Presence and Permanence of Salmonellae in Coastal Areas of Bahia de Todos Santos, Mexico. Appl Environ Microbiol 74 (October) (19): 5918-5924. http://www.pubmedcentral.nih.gov/articlerender.fcgi?artid=2565968\&tool=pmcentrez.

[24]. Wang, X., et al. 2008. Bayesian Spatio-Temporal Modeling of Schistosoma japonicum Prevalence Data in the Absence of a

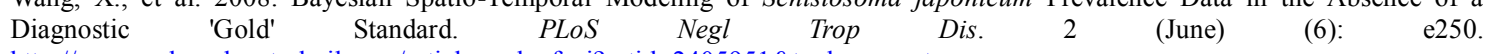
http://www.pubmedcentral.nih.gov/articlerender.fcgi?artid=2405951\&tool=pmcentrez.

[25]. Wassif S.M and Amany R.: Spot lights on the demographic profile of Egypt, The Egyptian journal of Community Medicine 2008Vol. 26, No.1

[26]. Wei Gu, Xin Wang, S Elizabeth McGregor, Optimization of preventive health care facility locations, Canada, 2010 